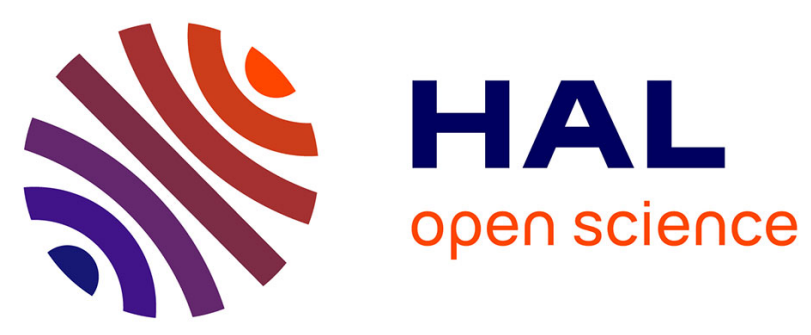

\title{
SiC-TiC nanocomposite for bulk solar absorbers applications: Effect of density and surface roughness on the optical properties
}

Héléne Arena, Moustapha Coulibaly, Audrey Soum-Glaude, Alban Jonchere, Adel Mesbah, Guilhem Arrachart, Nicolas Pradeilles, Marion Vandenhende, Alexandre Maitre, Xavier Deschanels

\section{To cite this version:}

Héléne Arena, Moustapha Coulibaly, Audrey Soum-Glaude, Alban Jonchere, Adel Mesbah, et al.. SiC-TiC nanocomposite for bulk solar absorbers applications: Effect of density and surface roughness on the optical properties. Solar Energy Materials and Solar Cells, 2019, 191, pp.199-208. 10.1016/j.solmat.2018.11.018 . hal-02001098

\section{HAL Id: hal-02001098 \\ https://hal.umontpellier.fr/hal-02001098}

Submitted on 3 Dec 2020

HAL is a multi-disciplinary open access archive for the deposit and dissemination of scientific research documents, whether they are published or not. The documents may come from teaching and research institutions in France or abroad, or from public or private research centers.
L'archive ouverte pluridisciplinaire HAL, est destinée au dépôt et à la diffusion de documents scientifiques de niveau recherche, publiés ou non, émanant des établissements d'enseignement et de recherche français ou étrangers, des laboratoires publics ou privés. 
5 Hélène Aréna ${ }^{1 *}$, Moustapha Coulibaly $^{1}$, Audrey Soum-Glaude ${ }^{2}$, Alban Jonchère ${ }^{1}$, Adel Mesbah ${ }^{1}$, 6 Guilhem Arrachart $^{1}$, Nicolas Pradeilles ${ }^{3}$, Marion Vandenhende ${ }^{3}$, Alexandre Maitre ${ }^{3}$, and Xavier 7 Deschanels $^{1}$

8

$9{ }^{1}$ ICSM, CEA, CNRS, ENSCM, Univ. Montpellier, Marcoule, 30207 Bagnols-sur-Cèze, France 10 helene.arena@cea.fr

11 xavier.deschanels@cea.fr

$12{ }^{2}$ PROMES-CNRS, UPR 8521, 7 rue du Four Solaire 66120 Font-Romeu Odeillo Via, France

$13{ }^{3}$ IRCER, UMR CNRS 7315, 87068 Limoges, France

14

15 Keywords: SiC ; TiC ; Concentrated Solar Power ; selectivity ; density ; roughness 16

\section{Abstract}

18 In this study, the potential of SiC-TiC nano-composites as solar absorbers has been studied. For solar 19 thermal applications, materials with high solar absorptance and low emittance are ideally sought for 20 (spectral selectivity). A semi-molecular sol-gel synthesis route leading to nanometric homogenous 21 composites was described. The resulting SiC-TiC nanocomposite powder was sintered at different 22 temperatures to produce samples with various relative densities (from 57 to $96 \%$ ). The samples 23 morphology and composition were characterised by several techniques including Scanning Electron 24 Microscopy (SEM), Energy-Dispersive X-Ray Spectroscopy (EDX), X-Ray Diffraction (XRD), 25 carbon and oxygen elemental analyses. The link between the surface roughness and the relative 26 density was precised and the effects on the optical properties ( 0.25 to $25 \mu \mathrm{m}$ wavelength range) were 27 studied. Comparisons were made with pure $\mathrm{SiC}$ and pure $\mathrm{TiC}$ samples with various relative densities. 28 Overall, the sample emittance was found to strongly decrease with the increase in the relative 29 density, leading to a great increase in the spectral selectivity, despite a little decrease in the solar 30 absorptance. The TiC-SiC composite has an intermediate reflectance compared to the pure $\mathrm{SiC}$ and 31 the pure TiC samples. With an absorptance of 0.76 , an emittance of 0.44 and a selectivity of 1.74 , the 32 denser SiC-TiC could be a good candidate for bulk solar applications. 


\section{1. Introduction}

36 The development of a sustainable, efficient and renewable energy power is a great challenge for our

37 generation. In this context, particular attention is given to concentrating solar power (CSP) as it is a 38 promising technology to improve the efficiency of the solar-to-electricity conversion $[1,2]$. In this 39 system, the absorber plays a key role by transferring the energy from solar radiation to a heat transfer 40 fluid (HTF), which will be used in a thermodynamical cycle to produce electricity. However, 41 because of thermal losses (by radiation, conduction and convection), the energy received by the 42 absorber is not completely transferred to the HTF. As the operating temperature of the absorber is 43 high (up to $1000^{\circ} \mathrm{C}$ ), the main energy losses are due to thermal radiation. Indeed, when the absorber 44 is heated, it can behave like a blackbody and emit radiation in the infrared wavelength region 45 towards its environment. To maximize the energy efficiency, the absorber should be spectrally 46 selective: absorbing a maximum of energy in the solar spectrum wavelength region $(0.25-2.5 \mu \mathrm{m})$, 47 while having a low thermal emittance in the IR region (above $2.5 \mu \mathrm{m}$ ), so that thermal re-radiation 48 losses by the heated absorber are kept low [3-6]. In addition to be spectrally selective, the material 49 constituting the absorber should be resistant to the extreme operating conditions under concentrated 50 solar irradiation (high temperatures, oxidative/corrosive atmospheres, thermal cycles, etc.).

52 Nowadays, one of the materials commonly used as high temperature absorber is silicon carbide, 53 because of its high oxidation resistance, its good mechanical properties and high sunlight 54 absorptance [7]. However, $\mathrm{SiC}$ is not spectrally selective as it has a high spectral emittance [8, 9]. 55 Transition metal carbides, nitrides and borides of column IV have been subject of many 56 investigations due to their inherent spectral selectivity [10-24]. Among these materials, titanium 57 carbide could be a good candidate because it is spectrally selective and it has good mechanical 58 properties. However, it also has a low resistance to oxidation [25-32]. Previous studies showed that 59 the combination of $\mathrm{SiC}$ and $\mathrm{TiC}$ in a nanocomposite material could be a good solution to obtain a 60 material that is spectrally selective as well as resistant to oxidation [33].

61 The literature reports the combination of $\mathrm{SiC}$ and $\mathrm{TiC}$ in a composite structure to produce materials 62 with higher relative density and improved mechanical properties (fracture toughness, Vickers 63 hardness), thermal and electrical conductivity [34-44]. These properties are required for the absorber 64 material as it will endure extreme operating conditions.

65

66 Several parameters have an impact on the optical properties of the materials.

67 First, the apparent density of the material leads to changes in the optical properties of the samples. 68 The apparent density results from the process used for the material elaboration and corresponds to 
69 porosity in the range of a few micrometers. Several studies indicate that the denser the material, the 70 higher the reflectance in the whole range of wavelengths. Dense materials have a little lower 71 absorptance $(\alpha)$ but above all a lower emittance $(\varepsilon)$, thus a higher spectral selectivity which is 72 defined as the ratio $\alpha / \varepsilon[19,20,23,45-47]$.

73 Second, the surface roughness increases the absorptance of radiations in the range of wavelength 74 lower than the average size of the holes and scratches (a few nanometers to a few hundred 75 nanometers) [5, 6, 20, 23, 46-50]. For example, the surface patterning of zirconium boride samples 76 by femtolaser led to better absorptance but also to higher emittance $[48,49]$. The increase in the 77 absorptance and in the emittance with the surface roughness was also noticed for $\mathrm{SiC}$ and $\mathrm{TiC}$ 78 samples, in a preliminary study reported in Supplementary Information 1.

79

80 In most studies concerning the optical properties of UHTCs (Ultra-High Temperature Ceramics),

81 densified or porous samples are obtained from commercial powders. To produce composites, several 82 powders are generally mixed and sintered together. However, mechanical mixing generally induces 83 inhomogeneities and sometimes impurities in the final composite. In the conventional process, TiC 84 and $\mathrm{SiC}$ are usually synthesized by the carbothermal reduction of $\mathrm{TiO}_{2}$ or $\mathrm{SiO}_{2}$ with carbon black. 85 This reaction requires high temperature $\left(1800-2200^{\circ} \mathrm{C}\right)$, long reaction time $(10-24 \mathrm{~h})$ and often 86 leads to coarse-grained powders [51-53]. With nano-sized particles, the temperature (and/or time) 87 needed for carbothermal reduction would decrease [54-58]. In addition, working with nano-sized 88 materials would improve the homogeneity of the final products and lead to an intimate mixture of $89 \mathrm{SiC}$ and $\mathrm{TiC}$ particles.

90 Molecular routes were proposed to create proximity between the metal and the carbon source by 91 bonding them into the same molecule. This procedure was successfully applied to SiC [59] but did 92 not lead to a complete carbothermal reduction for $\mathrm{TiC}$ and SiC-TiC composites [60-62]. In addition, 93 this route is complex and implies a thorough control of the synthesis conditions. Another way to 94 create proximity would be to trap the carbon source in the network of a polymer material by a sol-gel 95 process, before the carbothermal reduction. This route was applied to produce $\mathrm{TiC}, \mathrm{ZrC}-\mathrm{SiC}$ and 96 TiC-SiC materials [63-65]. The co-condensation of the two alkoxide precursors leads to 97 interpenetrated networks of the two oxides with enclosed carbon source particles. The carbothermal 98 reduction produced a homogenous nanocomposite with a good repartition of both carbides and small 99 size crystallites [66-68]. Sucrose is an interesting carbon source as it is cheap and highly soluble in 100 several media, it was successfully used by several authors $[33,56,57,69,70]$.

102 In this paper, we propose to associate $\mathrm{SiC}$ with $\mathrm{TiC}$ in a nanocomposite material for high temperature 103 bulk solar absorber applications. We present a synthesis route where the two metal oxide precursors 
104 copolymerize, in the presence of sucrose as the carbon source, leading to an intimate mixture. In 105 order to improve the optical and mechanical properties, the resulting powders were sintered by Spark 106 Plasma Sintering (SPS) to produce materials with various densities. The samples morphology and 107 composition were characterized by several techniques including Scanning Electron Microscopy 108 (SEM), Energy-Dispersive X-Ray Spectroscopy (EDX), X-Ray Diffraction (XRD), carbon and 109 oxygen elemental analyses. The effects of the material relative density and of its surface roughness 110 on the optical properties and spectral selectivity were studied by reflectance measurements in the 1110.25 to $25 \mu \mathrm{m}$ wavelength range. The results were compared to those of pure $\mathrm{SiC}$ and pure TiC with 112 various densities.

\section{3}

\section{2. Material and methods}

\section{$115 \quad$ 2.1. Semi-molecular route}

116 The objective was to create an intimate mixture of the two metal oxide precursors and the carbon 117 source during the gelling. As the precursors have a different reactivity, capping agents like 118 carboxylic acids, acetylacetone or ethylene glycol can be used to modify the surface chemistry of the 119 precursors and lower their reactivity [71-74]. The synthesis route is described on Figure 1 and 120 detailed in Supplementary Information 2. Titanium isopropoxide (TTIP) and tetraethyl orthosilicate 121 (TEOS) were chosen as the source of titanium and silicon, respectively. The system was kept under 122 inert atmosphere by nitrogen flow to prevent unintended reactions among the raw materials and 123 water. All additions were made dropwise under continuous stirring and heating at $90^{\circ} \mathrm{C}$. Because 124 TTIP is much more reactive than TEOS, its reactivity was first lowered by complexation with citric 125 acid dissolved in absolute ethanol. Then, TEOS was added to the mixture, followed by sucrose 126 dissolved into water. The co-condensation was favored by the addition of sodium fluoride. The 127 solution was first concentrated under vacuum distillation and the resulting gel was freeze dried, 128 grounded and sifted to produce a homogeneous powder. 


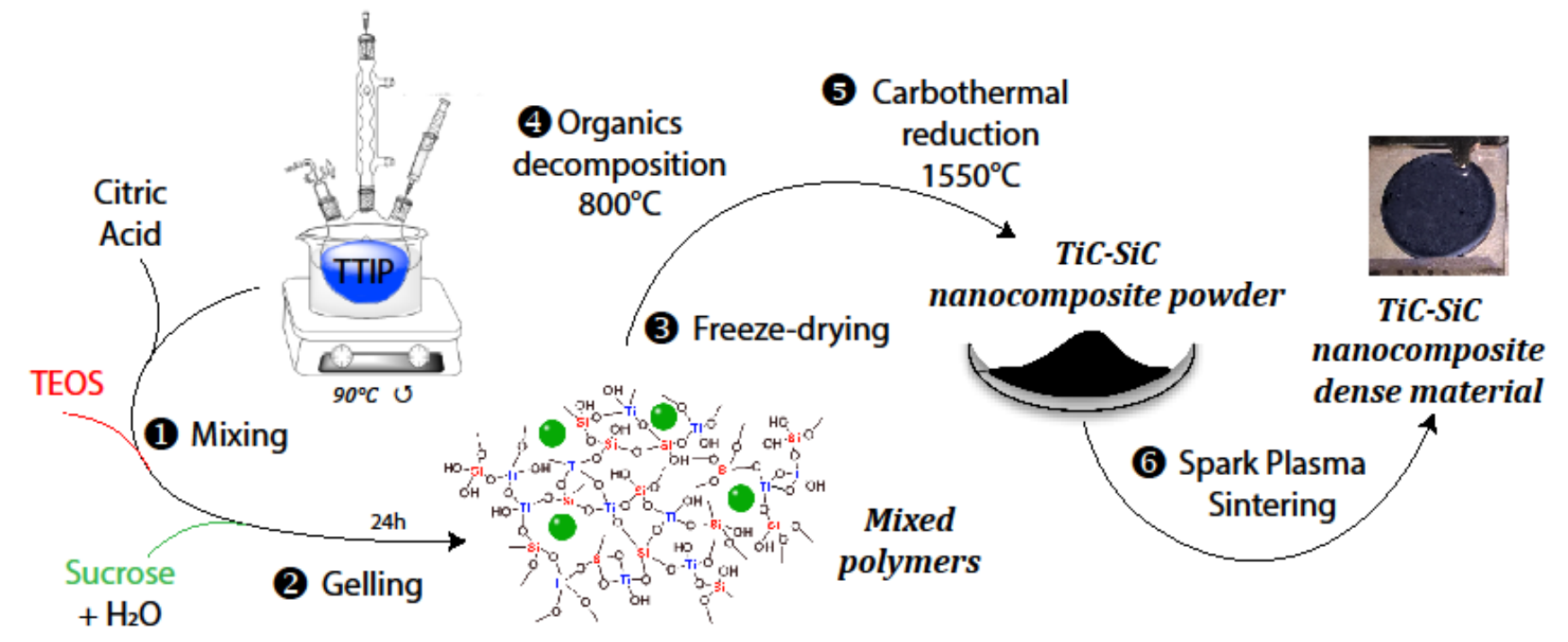

Figure 1: Reaction scheme of the synthesis route

132

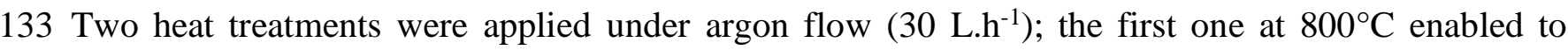
134 decompose the organic parts of the precursors (sucrose and citric acid) into carbon. According to 135 Equation (1), the decomposition of one equivalent of sucrose could provide for a maximum of 12 136 equivalents of carbon. However, according to the literature, the decomposition of sucrose leads to the 137 formation of various carbon gaseous compounds $\left(\mathrm{CH}_{4}, \mathrm{C}_{\mathrm{n}} \mathrm{H}_{2 n}, \mathrm{CO}_{2} \ldots\right)$, leaving about $48 \%$ of 138 efficient carbon [33]. Similarly, the decomposition of one equivalent of citric acid could provide for 139 a maximum of 6 equivalents of carbon (Equation 2). According to several studies [75-77], after the 140 melting of citric acid at $153^{\circ} \mathrm{C}$, this compound decomposes into aconitic acid and then in citra/ita141 conic anhydride by dehydration and decarboxylation reactions in the range of $160-270^{\circ} \mathrm{C}$. At higher 142 temperature, several gaseous compounds are formed and the proportion of residual carbon ranges 143 between 5 and $45 \%$. The amount of residual carbon depends on the processing parameters, heating 144 rate especially, but also on the complexation of citric acid with metallic element [74]. When they are 145 mixed with the other components of the synthesis, the behavior of sucrose and citric acid may be 146 different than when they are heated alone. The second heat treatment at $1550^{\circ} \mathrm{C}$ led to the 147 carbothermal reduction of oxides into carbides according to Equation 3.

149 Sucrose and citric acid decomposition $-\mathrm{T}=800^{\circ} \mathrm{C}$

$$
\left\{\begin{aligned}
C_{12} \mathrm{H}_{22} \mathrm{O}_{11(s)} & \rightarrow \mathbf{1 2} \boldsymbol{C}_{(s)}+11 \mathrm{H}_{2} \mathrm{O}_{(g)} \\
\mathrm{C}_{6} \mathrm{H}_{8} \mathrm{O}_{7(s)} & \rightarrow \mathbf{6} C_{(s)}+4 \mathrm{H}_{2} O_{(g)}+\frac{3}{2} O_{2}(g)
\end{aligned}\right.
$$

152 Carbothermal reduction $-\boldsymbol{T}=1550^{\circ} \mathrm{C}$

$$
\mathrm{MO}_{2(s)}+3 \mathrm{C}_{(s)} \rightarrow \mathrm{MC}_{(s)}+2 \mathrm{CO}_{(g)}
$$




$$
F=\frac{n_{T i}}{n_{T i}+n_{S i}}=\frac{n_{T T I P}}{n_{T T I P}+n_{T E O S}}=30 \%
$$

155

156 The ratio $\mathrm{R}$ (Equation 4) quantifies the carbon content resulting from the decomposition of sucrose 157 and citric acid according to the Equations (1) and (2). Because the decomposition of sucrose and 158 citric acid produces not only effective carbon but also carbon gaseous species, the amount of carbon 159 available for the carbothermal reduction is not easily predictable and varies depending on the 160 conditions. The value of the $\mathrm{R}$ ratio leading to a stoichiometric carbothermal reaction is empirical. 161 According to preliminary studies, the $\mathrm{R}$ ratio was chosen to be 2.19 [60]. The $\mathrm{F}$ ratio defines the 162 relative proportions of $\mathrm{Ti}$ and $\mathrm{Si}$ in the final material (Equation 5). The amounts of TEOS and TTIP 163 used in the synthesis were adapted to produce a $30 \%$ at $\mathrm{TiC}-70 \%$ at $\mathrm{SiC}$ composite, with an atomic $\mathrm{F}$ 164 ratio of $30 \%$.

165

\subsection{Shaping}

\section{Sintering}

168 To produce materials with various densities, Spark Plasma Sintering process was used on the 169 composite powder resulting from the semi molecular route. Reference samples of pure TiC and pure $170 \mathrm{SiC}$ were also made from $\mathrm{TiC}(98 \%)$ and $\mathrm{SiC}(97.5 \%)$ powders supplied by Sigma-Aldrich with an 171 average particle size of $3 \mu \mathrm{m}$ and $17 \mu \mathrm{m}$, respectively. Sintering was conducted by Spark Plasma 172 Sintering apparatus (Fuji-Syntex, Dr Sinter 825, Japan) under dynamic vacuum to avoid grain 173 growth. A sufficient amount of powder was poured into a graphite die with an inner diameter of 20.4 $174 \mathrm{~mm}$. A compressive graphite foil (0.2 mm thick, Papyex@, Mersen Goup, France) was used as 175 lubricant to coat the inner surface of the die and the surface of the punches. The powder was heated 176 under vacuum to a maximal temperature between $1300^{\circ} \mathrm{C}$ to $1950^{\circ} \mathrm{C}$ for 5 minutes with a heating 177 rate of $200^{\circ} \mathrm{C} / \mathrm{min}$. The heating rate was decreased at $50^{\circ} \mathrm{C} / \mathrm{min}$ the last minute of heating, to avoid 178 an overshoot. A uniaxial pressure of $75 \mathrm{MPa}$ was applied upon heating. Cooling rate was $179100^{\circ} \mathrm{C} / \mathrm{min}$. SPS is commonly used to sinter Ultra High Temperature Ceramics $[78,79]$.

\section{$\underline{\text { Polishing }}$}

182 To produce mirror polished surfaces, the densified materials were polished with a Beta Buehler 183 grinder-polisher, with SiC grinding papers and with $1 \mu \mathrm{m}$ diamond paste (Struers) according to the 184 procedure described in Table 1. To study the effects of surface roughness on the optical properties, 185 the surface of several samples was scratched with $\mathrm{SiC}$ grinding papers with increasing grain size, the 186 results of this preliminary study are given in Supplementary Information 1. 


\begin{tabular}{|c|c|c|c|c|}
\hline \multirow{2}{*}{ Polishing step } & \multicolumn{2}{|c|}{ Grinding SiC paper } & \multirow{2}{*}{ Rotation speed (rpm) } & \multirow{2}{*}{ Time (min) } \\
\cline { 2 - 5 } & Grit (grain/cm $\left.\mathbf{c m}^{2}\right)$ & Grain size $(\boldsymbol{\mu m})$ & 200 & 2 \\
\hline 1 & 1200 & 15.3 & 200 & 5 \\
\hline 2 & 2000 & 10.3 & 200 & $5-10$ \\
\hline 3 & 4000 & 5 & 200 & $15-20$ \\
\hline 4 & Diamond & 1 & & \\
\hline
\end{tabular}

Table 1: Polishing procedure.

188

\subsection{Characterization methods}

Optical properties

191 Two spectrophotometers were used to measure the total spectral reflectance of the samples. Over the

192 wavelength range from 0.25 to $2.5 \mu \mathrm{m}$, the near-normal hemispherical ( $R^{\perp, \cap}$ ) reflection spectrum

193 was acquired with a $10 \mathrm{~nm}$ step using a Perkin Elmer Lambda 950 spectrophotometer. This apparatus

194 was equipped with deuterium and tungsten lamps, PMT and InGaAs detectors, and a $150 \mathrm{~mm}$ 195 integrating sphere coated with Spectralon diffuse reflective coating. The sample was illuminated at 196 an incidence angle of $8^{\circ}$.

197 Over the wavelength range from $1.25 \mu \mathrm{m}$ to $25 \mu \mathrm{m}$, the hemispherical directional reflectance $\left(R^{\cap, \theta}\right)$ 198 was recorded at different detection angles $\theta$ from 8 to $80^{\circ}$, using a SOC-100 HDR reflectometer 199 (Surface Optics Corporation) coupled with a Nicolet (Fourier Transform InfraRed spectroscopy) 200 FTIR 6700 spectrophotometer. A gold coated calibrated specular reflectance standard was used as 201 reference during measurements (NIST calibration). The spectral range from 1.25 to $25 \mu \mathrm{m}$ was 202 covered by a FTIR equipped with InGaAs and DTGS/KBr detectors, coupled with Quartz and $\mathrm{KBr}$ 203 beamsplitters, respectively. The sample was illuminated from all directions using a $700^{\circ} \mathrm{C}(973 \mathrm{~K})$ 204 blackbody as the infrared source and a $2 \pi$ imaging gold coated hemi ellipsoid. The light reflected by 205 the sample at a chosen detection angle was collected by a moveable overhead mirror which directed 206 the collimated beam into the FTIR apparatus for signal treatment to retrieve the reflectance spectrum.

207 Each reflectance spectrum was derived from 64 consecutive scans on the same sample.

208 The total spectral reflectance measured and the solar spectrum were interpolated over the wavelength 209 range from 0.25 to $25 \mu \mathrm{m}$ with a step of $2 \mathrm{~nm}$ to calculate the optical parameters, using Mathematica 210 software. The solar absorptance $\alpha$ was calculated from room temperature measurements in the 211 wavelength range 0.25 to $4 \mu \mathrm{m}$, according to Equation 6 . The near-normal thermal emittance $\varepsilon_{\vartheta}\left(T_{a}\right)$ 212 and the hemispherical emittance $\varepsilon_{H}\left(T_{a}\right)$ at room temperature were calculated in the wavelength 213 range 1.25 to $25 \mu \mathrm{m}$ according to Equations 7 and 8 respectively. The hemispherical emittance 214 represents the propensity of a surface illuminated from all directions of the hemisphere surrounding 
215 it to reemit radiation in the same hemisphere. As reported in the results section, at room temperature 216 and for this type of samples, the emittance calculated from near-normal reflectance measurement is 217 representative of the hemispherical emittance. Spectral transmittance was not measured, as the 218 samples were opaque over the whole considered spectral range.

219

$220 \quad \alpha=\frac{\int_{0.25 \mu m}^{4 \mu m}\left[1-R_{8^{\circ}}\left(\lambda, T_{a}\right)\right] \cdot G(\lambda) \cdot d \lambda}{\int_{0.25 \mu m}^{4 \mu m} G(\lambda) \cdot d \lambda}$

$$
\varepsilon_{\theta}\left(\theta, T_{a}\right)=\frac{\int_{1.25 \mu m}^{25 \mu m}\left[1-R\left(\lambda, T_{a}, \theta\right)\right] \cdot P\left(\lambda, T_{a}\right) \cdot d \lambda}{\int_{0.25 \mu m}^{25 \mu m} P\left(\lambda, T_{a}\right) \cdot d \lambda}
$$

$$
\varepsilon_{H}\left(T_{a}\right)=2 \int_{0}^{\pi / 2} \varepsilon_{\theta}\left(\theta, T_{a}\right) \cdot \sin \theta \cdot \cos \theta \cdot d \theta
$$

222 With $\lambda$ : the wavelength $[\mu \mathrm{m}], R_{8^{\circ}}\left(\lambda, T_{a}\right)$ and $R\left(\lambda, T_{a}, \theta\right)$ : the spectral reflectance of the sample 223 measured at room temperature $\left(T_{a}\right)$ with an illumination angle of $8^{\circ}$ or with a variable detection angle $224 \theta, G(\lambda)$ : the standard solar irradiance spectrum (ASTM-G173 AM1.5 direct + circumsolar) [W.m $\left.225^{2} . \mu \mathrm{m}\right], P\left(\lambda, T_{a}\right)$ : spectral emittance (exitance) of a blackbody at room temperature derived from 226 Planck's law $\left[\mathrm{W} \cdot \mathrm{m}^{-2} \cdot \mu \mathrm{m}\right]$.

228 The apparent density ( $\rho_{\text {app. }}$ ) of the sintered samples was measured by hydrostatic weighting in pure 229 water, using Archimedes method. Helium pycnometry measurements were conducted to determine 230 the pycnometric density ( $\rho_{\text {pycno. }}$ ). The theoretical density ( $\rho_{\text {th. }}$ ) of the mixed carbide materials was 231 calculated using a rule of mixtures taking into account the $\mathrm{Si} / \mathrm{Ti}$ measured proportions and the 232 amounts of free $\mathrm{C}$ and $\mathrm{O}$. These densities were used to determine the relative density (D), the open 233 and closed porosities ( $\phi_{\text {open }}$ and $\phi_{\text {closed }}$ ) according to the equations reported in Supplementary 234 Information 3.

235 The surface roughness of the materials was measured by means of optical interferometry (Fogale 236 Nanotech - Microsurf 3D). This apparatus gives the global roughness of a $287 \mu \mathrm{m}$ x $481 \mu \mathrm{m}$ area. 237 For each sample, a least six areas were measured to obtain an average roughness value.

239 The morphology of the samples was studied by Scanning Electron Microscopy (SEM), with an FEI 240 Quanta 200 ESEM equipped with a Field Emission Gun. SEM images were recorded with back241 scattered electrons (BSE) for composite samples and with secondary electrons (SE) for pure TiC and 242 SiC samples. Energy Dispersive Spectra (EDX) were recorded using a Bruker SDD 5030 detector 243 with a $123 \mathrm{eV}$ resolution at the $\mathrm{Mn}(\mathrm{K} \alpha)$ line. EDX was used to verify the composition of the 244 synthesized products and to study the effects of oxidation.

245 The global Ti/Si proportion was also measured by X-Ray Fluorescence (XRF), using a Spectro246 Xepos apparatus with four secondary targets (Mo, $\mathrm{Al}_{2} \mathrm{O}_{3}$, Co and HOPG Bragg crystal). 
247 Carbon and Oxygen analyzers (LECO CS230 and ON736) were used to measure the total carbon and 248 oxygen contents, respectively. The samples were heated under an oxygen flow for carbon analysis or 249 in a graphite environment for oxygen analysis. In both cases, the formation of carbon oxides was 250 detected and quantified by infrared spectroscopy, then related to the total carbon or oxygen content 251 in the samples. Added Fe powder was used to assist the combustion in the case of carbon analysis.

253 The samples were characterized by X-Ray Diffraction (XRD) using the Bruker D8 advance 254 diffractometer equipped with lynxeye detector and using $\mathrm{Cu} \mathrm{K} \alpha$ radiation $(\lambda=1.54184 \AA)$. Data were 255 acquired in reflection geometry (parallel beam) in the $10-110^{\circ}(2 \theta)$ or $10-90^{\circ}(2 \theta)$ range of angles 256 with steps of $0.019^{\circ}$. Silicon powder was collected and used as standard to evaluate the instrumental 257 function. All the collected XRD patterns were refined by the Rietveld method with the use of the 258 Fullprof suite package [80, 81]. TiC compound was found to crystallize in the cubic $\mathrm{NaCl}$ structure 259 type in the $\mathrm{Fm}-3 \mathrm{~m}$ space group, whereas $\mathrm{SiC}$ crystallizes in the $\mathrm{ZnS}$ structure type in the $\mathrm{F}-43 \mathrm{~m}$ 260 space group. During the refinement, several profile/structure parameters were allowed to vary such 261 as zero shift, scale factor, isotropic thermal factor, unit cell parameters, moreover an anisotropic size 262 model was applied in order to evaluate the microstructural effect. An example of the results of the 263 Rietveld refinement obtained for the TiC compound with a relative density of $78 \%$ is available in 264 Supplementary Information 4.

265

266 3. Results

\subsection{Characterization of the final products}

268 All the results concerning the composition and the physical shape of the samples are reported in 269 Table 2.

\begin{tabular}{|c|c|c|c|c|c|c|c|c|}
\hline \multirow{2}{*}{ Sample } & $\begin{array}{c}\text { Processing } \\
\text { parameters }\end{array}$ & \multicolumn{3}{|c|}{ Composition } & \multicolumn{3}{c|}{ Sintered materials characteristics } \\
\cline { 2 - 10 } & $\begin{array}{c}\text { T sintering } \\
\left({ }^{\circ} \text { C) }\right.\end{array}$ & $\begin{array}{c}\text { Ti/Si } \\
\text { proportion } \\
(\% \text { mol })\end{array}$ & $\begin{array}{c}\text { C } \\
(\% \text { mass })\end{array}$ & $\begin{array}{c}\text { O } \\
(\% \text { mass })\end{array}$ & $\begin{array}{c}\text { Relative } \\
\text { density } \\
(\%)\end{array}$ & $\begin{array}{c}\text { Open } \\
\text { porosity } \\
(\%)\end{array}$ & $\begin{array}{c}\text { Closed } \\
\text { porosity (\%) }\end{array}$ & $\begin{array}{c}\text { Surface } \\
\text { roughness } \\
(\mathbf{n m})\end{array}$ \\
\hline TS-57 & 1450 & $31 / 69$ & 26.6 & 7.2 & 56.6 & 43.4 & 0 & 52 \\
\hline TS-82 & 1550 & $32 / 68$ & 25.3 & 5.5 & 81.6 & 16.7 & 1.8 & 20 \\
\hline TS-92 & 1650 & $31 / 69$ & 26.2 & 6.0 & 92.3 & 6.3 & 1.4 & 13 \\
\hline TS-96 & 1750 & $32 / 68$ & 26.0 & 5.0 & 95.8 & 1.2 & 3.1 & 10 \\
\hline TiC-78 & 1300 & $100 / 0$ & 20.0 & 0.67 & 77.9 & 19.1 & 3.0 & 38 \\
\hline TiC-91 & 1400 & $100 / 0$ & 20.7 & 0.56 & 90.5 & 6.9 & 2.6 & 11 \\
\hline TiC-94 & 1500 & $100 / 0$ & 19.5 & 0.54 & 94.4 & 2.7 & 2.9 & 17 \\
\hline TiC-96 & 1700 & $100 / 0$ & 19.6 & 0.47 & 95.8 & 1.5 & 2.8 & 15 \\
\hline TiC-97 & 1850 & $100 / 0$ & 19.6 & 0.46 & 96.6 & 1.1 & 2.4 & 6 \\
\hline SiC-72 & 1950 & $0 / 100$ & 30.4 & 0.20 & 72.1 & 26.5 & 1.4 & 24 \\
\hline
\end{tabular}


Table 2: Composition and measured characteristics of materials after SPS sintering for 5 min at $P=75 M P a$ at the sintering temperature indicated in the table. Ti/Si proportion was obtained by average between XRF and SEM-EDX analyses. The theoretical \%mass of C is $26 \%, 20 \%$ and $30 \%$, for TS composites, pure TiC and pure SiC samples,

273 respectively. The error is about $0.1 \%$ for elemental analyses, relative density, and open and closed porosity. The error is 274 about $1 \mathrm{~nm}$ for surface roughness and about $1 \%$ at for Ti/Si proportion.

275

276 The XRF and EDX analyses reported on Supplementary Information 5 indicate a Ti / Si proportion, 277 respectively higher and lower than the theoretical values. Nevertheless, the average values (Table 2) 278 are close to the theoretical ones, the synthesized composites have the expected $\mathrm{Ti} / \mathrm{Si}$ proportion. 279 The amount of $\mathrm{C}$ globally decreases with the increase in the sintering temperature. The amount of $\mathrm{C}$ 280 is close to the theoretical value $(27 \%, 20 \%$ and $30 \%$, for TS composites, pure TiC and pure SiC 281 samples, respectively) and the $\mathrm{O}$ content is higher for the composite than for the pure TiC and SiC. 282 This high $\mathrm{O}$ content could be due to a unsufficient amount of $\mathrm{C}$ available for the carboreduction after 283 the sucrose decomposition at $800^{\circ} \mathrm{C}$. Another explanation could be a too low temperature for the 284 carboreduction, as the $\mathrm{O}$ content tends to decrease when the sintering temperature increases.

286 As expected, the relative density of the materials increases with the sintering temperature (Figure 2287 a) [43, 82-84]. For the pure $\mathrm{SiC}$ sample, full relative density could not be achieved, even with a 288 sintering temperature of $1950^{\circ} \mathrm{C}$. $\mathrm{SiC}$ is known to be difficult to sinter because of its highly covalent 289 bonded characteristic and the resulting low self-diffusion coefficient $[85,86]$.

290 For all samples, the open porosity decreases when increasing the sintering temperature and therby 291 with the relative density (Table 2). In the case of the composite samples, the closed porosity 292 increases with the sintering temperature and thereby with the relative density, while it remains 293 constant in the case of TiC samples (Table 2). During the sintering some of the open pores are 294 closed, leading to an increase of the closed porosity.

295 The relative density of all samples appear to be correlated with the surface roughness (Figure 2-b). 296 The evolutions are almost linear for the denser materials with the exception of sample TiC-91 which 297 shows a surprisingly low value of surface roughness $(11 \mathrm{~nm})$. The slope of the curve is much higher 298 for TS composites than for the pure TiC samples, meaning that the decrease in the relative density 299 induces a stronger increase in surface roughness for pure TiC samples. The open porosity consists in 300 surface holes which are partly taken into account in the value of the surface roughness. 


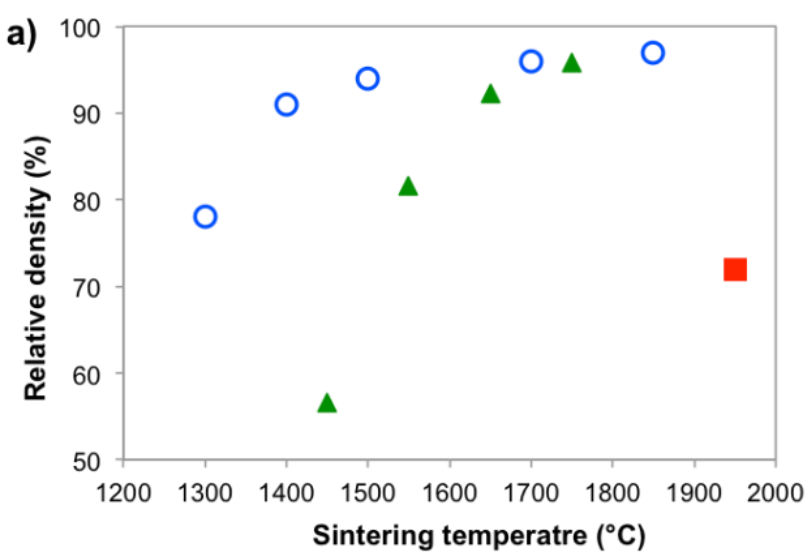

302

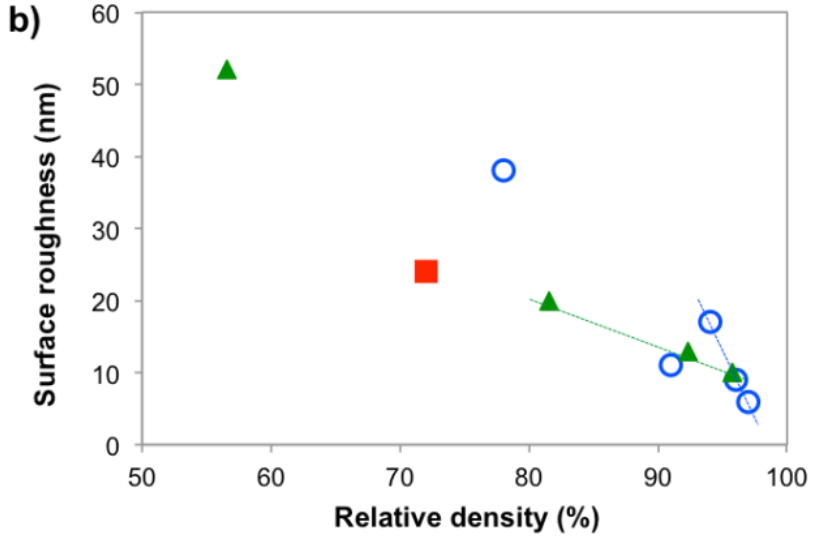

O Pure TiC

Pure SiC

303 Figure 2: a) Evolution of the relative density as a function of the sintering temperature and b) evolution of the surface 304 roughness as a function of the relative density. The dashed lines in b) are a guide for the eyes.

306 The morphology of the sintered materials was characterized by SEM to study the TiC and $\mathrm{SiC}$ grains

307 size and distribution (Figure 3). All composites present large areas with various electronic contrasts 308 due to changes in porosity and/or in composition. With the exception of sample TS-57, the electronic 309 contrast between the TiC grains (white) and the SiC matrix (gray) is marked (Figure 3-b to d). The 310 repartition of $\mathrm{TiC}$ grains within the $\mathrm{SiC}$ matrix is globally homogeneous at a short range while 311 presenting slight variations from one area to another. The presence of open porosity is confirmed by 312 SEM observation. The pore size is about $1 \mu \mathrm{m}$ or lower for most samples, and several microns for 313 the samples with the lowest densities (SiC, TS-57, TiC-78). In TS-57, it is not possible to distinguish $314 \mathrm{TiC}$ from SiC grains, the morphology of the sample surface looks like those of non sintered powders 315 (see Supplementary Information 6) which could be due to the low relative density of the sample. In 316 all composites excepted TS-57, the TiC grains have the same size (about $150 \mathrm{~nm}$ ). However, when 317 increasing the sintering temperature and thereby the relative density of the sample, the TiC grains are 318 brought closer, forming bigger white zones with less overall porosity.

319 In the case of the pure SiC sample (Figure 3-e), the grains are much bigger (about $17 \mu \mathrm{m}$ ) and the 320 open porosity is obvious. In the case of the TiC samples, the grains are smaller (about $3 \mu \mathrm{m}$ ) and the 321 decrease in open porosity is also visible in the SEM images (Figure 3-f to j). 


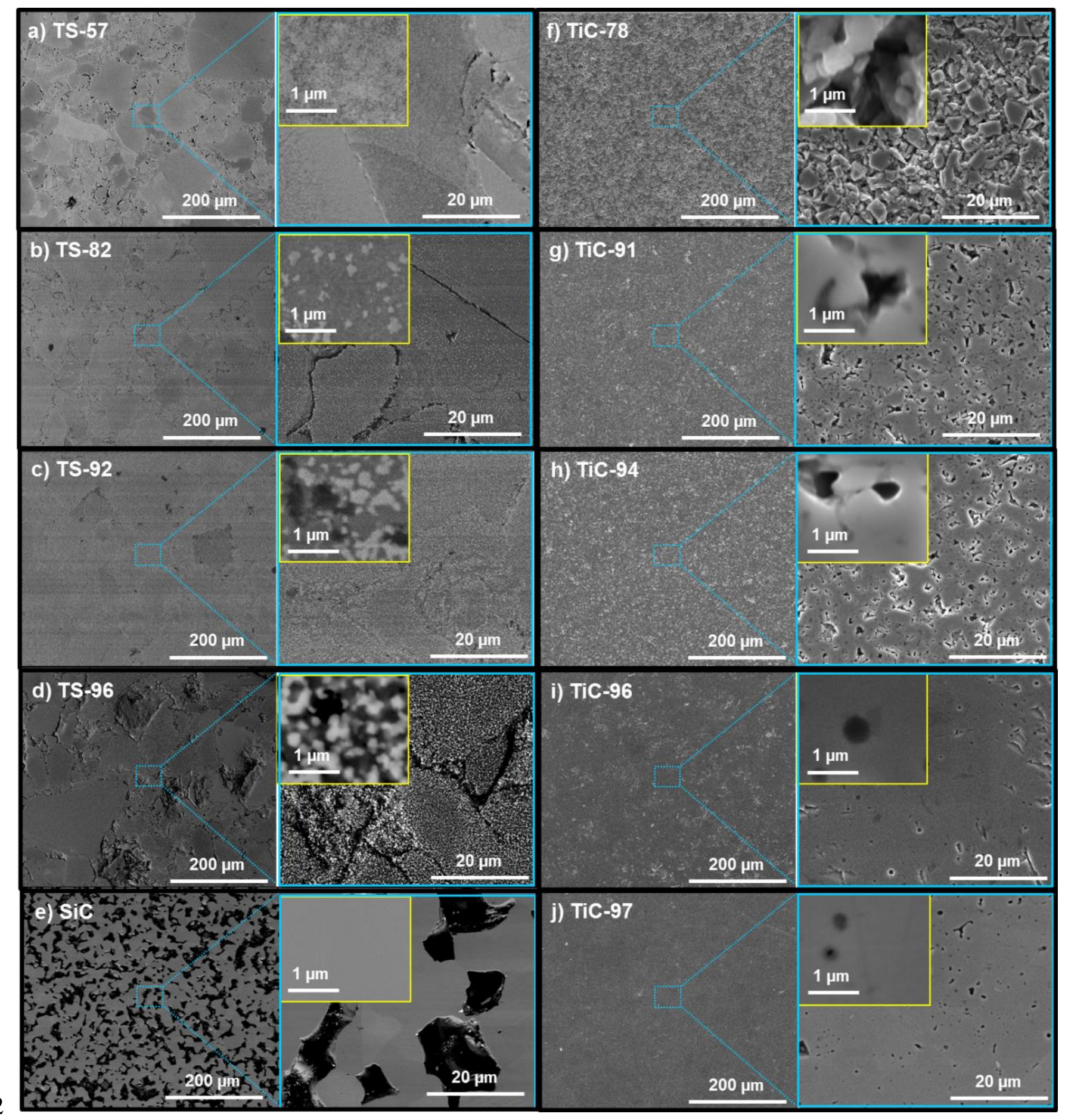

323 Figure 3: SEM images of the surface of the composite samples in BSE mode to show the Ti/Si distribution (a-d), the SiC 324 reference $(e)$ and the TiC samples $(f-j)$ in SE mode to show the topography since there is a unique carbide phase.

326 After sintering, the samples were also analyzed by PXRD (Figure 4-a, b) and the results of the 327 Rietveld refinement are presented in Figure 4-c, d) and in Table 3.

328 In the case of pure TiC samples, almost all the collected data showed the formation of pure and 329 single phase. In the case of sample TiC-94, there is a reflexion around $2 \theta=10^{\circ}$ which makes the 330 Rietveld refinement impossible. From the data reported in Table 3; the obtained TiC compounds are 331 almost free from $\mathrm{O}$ contamination and the $\mathrm{O}$ content decreases with the increase in the sintering 
332 temperature. These results are in good aggrement with the values determined by $\mathrm{O}$ elemental 333 analysis. The lattice volume of $\mathrm{TiC}$ is similar whatever the sample relative density and consistent 334 with the bibliography (Figure 4-c) [87]. Unfortunately, in the pure SiC sample sintered from the 335 commercial powder, the $\mathrm{SiC}$ phase cristallizes in the hexagonal system in several polymorphs which 336 making the Rietveld refinement impossible.

337

338 In the case of the SiC-TiC composites, both $\mathrm{TiC}$ and $\mathrm{SiC}$ cubic phases are present (Figure 4-b). 339 However, the possible incorporation of low amounts of $\mathrm{Si}$ in the TiC cubic structure (Ti or $\mathrm{C}$ sites) 340 [88] makes the Rietveld refinement complex to interpret and it was not possible to calculate precisely 341 the $\mathrm{O}$ content. The $\mathrm{TiC}$ and $\mathrm{SiC}$ unit cell parameters increase with the sintering temperature and 342 therefore with the sample relative density (Figure 4-d). One explanation could be the elimination of 343 the residual oxygen within the structure of both $\mathrm{TiC}$ and $\mathrm{SiC}$ phases as the sintering temperature 344 increases.
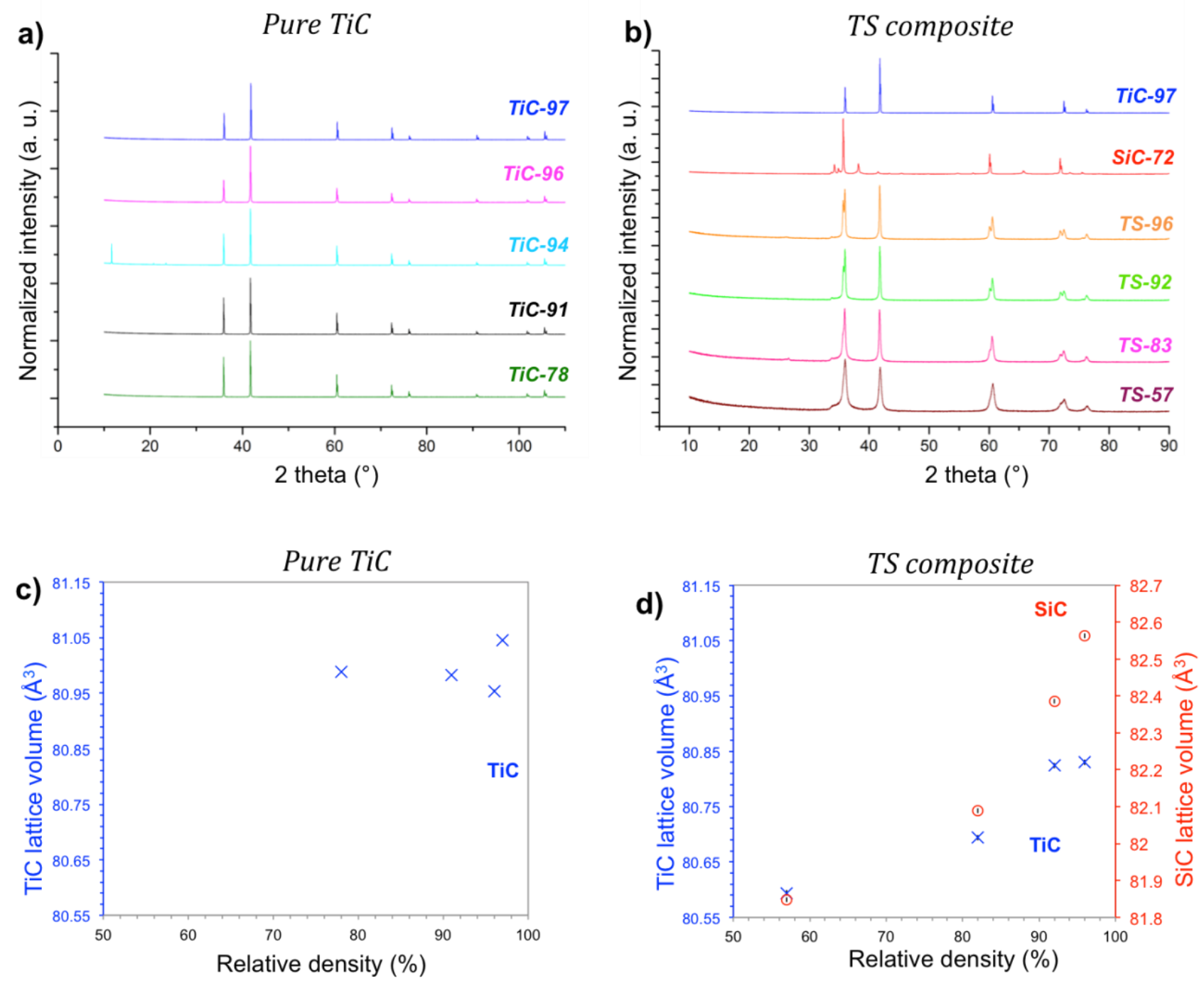

Figure 4: $a, b) X$-ray diffractograms of all the samples of this study and c, d) evolution of the TiC and $\mathrm{SiC}$ volume parameters as a function of the sample density. In c) and d), the error is about $10^{-3} \AA^{3}$. 


\begin{tabular}{|c|c|c|c|c|c|c|}
\hline Sample & $\begin{array}{c}\text { T sintering } \\
\left({ }^{\circ} \mathbf{C}\right)\end{array}$ & $\begin{array}{c}\text { Relative } \\
\text { density (\%) }\end{array}$ & $\begin{array}{c}O(\% \text { wt }) \\
\text { elemental analysis }\end{array}$ & $\begin{array}{l}O(\% w t) \\
\text { XRD }\end{array}$ & $\begin{array}{c}\text { TiC lattice } \\
\text { volume }\left(\AA^{3}\right)\end{array}$ & $\begin{array}{c}\text { SiC lattice } \\
\text { volume }\left(\AA^{3}\right)\end{array}$ \\
\hline TS-57 & 1450 & 56.6 & 7.2 & - & 80.594 & 81.848 \\
\hline TS-82 & 1550 & 81.6 & 5.5 & - & 80.694 & 82.088 \\
\hline TS-92 & 1650 & 92.3 & 6.0 & - & 80.824 & 82.386 \\
\hline TS-96 & 1750 & 95.8 & 5.0 & - & 80.83 & 82.562 \\
\hline TiC-78 & 1300 & 77.9 & 0.67 & 0.69 & 80.988 & - \\
\hline TiC-91 & 1400 & 90.5 & 0.56 & 0.54 & 80.983 & - \\
\hline TiC-94 & 1500 & 94.4 & 0.54 & - & - & - \\
\hline TiC-96 & 1700 & 95.8 & 0.47 & 0.51 & 80.954 & - \\
\hline TiC-97 & 1850 & 96.6 & 0.46 & 0.15 & 81.045 & - \\
\hline $\mathrm{SiC}-72$ & 1950 & 72.1 & 0.20 & - & - & - \\
\hline
\end{tabular}

Table 3 : Data obtained by Rietveld refinement from PXRD measurements: TiC and SiC lattice volumes and $O \%$ wt.

\subsection{Optical properties}

353 To evaluate the optical properties of the samples, the total spectral reflectance was measured in the 3540.25 to $25 \mu \mathrm{m}$ wavelength range with a near normal detection $\left(8^{\circ}\right.$ ) (Figure 5). It appears that the 355 reflectance of the pure TiC samples increases with the relative density, in the whole wavelength 356 range. The effect is small between the samples with close densities (TiC-97 to TiC-91) and more 357 marked with the less dense sample TiC-78. The reflectance of SiC is much lower than those of $\mathrm{TiC}$ 358 samples and displays the characteristic peak in the 10-14 $\mu \mathrm{m}$ range. In the case of the TS composite, 359 the reflectance curves are located between those of pure $\mathrm{TiC}$ and pure $\mathrm{SiC}$ and also display the $\mathrm{SiC}$ 360 characteristic peak. The reflectance increases with the relative density of the sintered TS composite 361 and the curves of the samples sintered at $1650^{\circ} \mathrm{C}$ and $1750^{\circ} \mathrm{C}$ (TS92 and $\mathrm{TS} 96$ ) are almost 362 superimposed.

363

Pure TiC and SiC

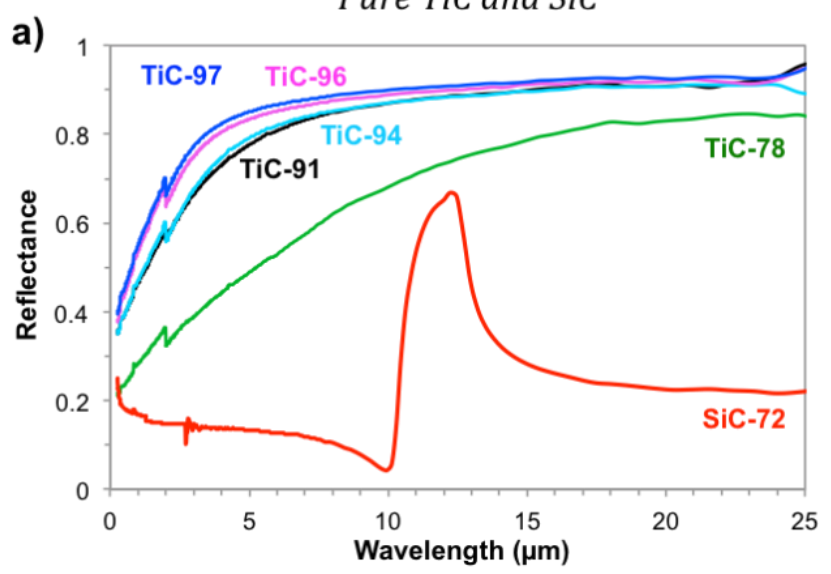

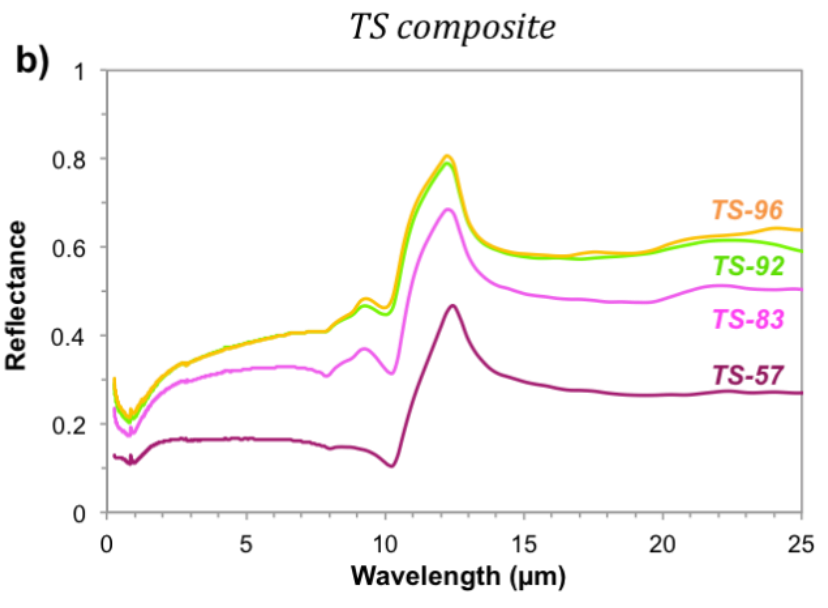

365 Figure 5: Evolution of the total near normal spectral reflectance for a) the pure TiC and SiC, and b) the TS composites. 


\section{4. Discussion}

\section{8}

369 These materials are sought for constituting the absorber in concentrating solar power devices. In this 370 context, they must fulfil several characteristics including good optical properties and good oxidation 371 resistance. From the results presented above, the effects of the relative density and of the surface 372 roughness on the optical properties are discussed below. However, the effects on the oxidation 373 resistance were not studied here. Coulibaly et al. showed that TiC-SiC composite materials have a 374 better oxidation resistance than pure $\mathrm{TiC}$ [33] and on-going work should bring new information 375 about this topic.

\section{6}

\section{Effects of the sintering temperature on the material relative density, composition and structure}

378 The TiC samples on one hand, and the composite samples on the other hand, were sintered from the 379 same powders (commercial product and synthesised by semi-molecular route, respectively) at a 380 temperature ranging from 1300 to $1850^{\circ} \mathrm{C}$. As presented in Table 2 and Figure 2, the relative density 381 of the final material increased with the increase in the sintering temperature. Sintering did not 382 induced the emergence of secondary phases, at least not in a sufficient amount to be detected by 383 XRD (Figure 4). In the case of the composite, the sintering process did not modify the overall Si-Ti 384 proportion (Table 2) or induce $\mathrm{TiC}$ grain growth. However, it favored their aggregation (in denser 385 samples, TiC grains distribution is less homogeneous) (Figure 3). In addition, the increase in 386 sintering temperature lowered the total $\mathrm{O}$ content in the final material which increased the volume of 387 the TiC lattice towards the one obtained for the pure TiC samples. This increase in volume is 388 consitent with the higher atomic radius of $\mathrm{C}$ compared to $\mathrm{O}$. This result is in agreement with several 389 studies about the evolution of lattice parameter of $\mathrm{TiC}_{\mathrm{x}} \mathrm{O}_{(1-\mathrm{x})}$ oxycarbide materials as a function of the 390 composition $[87,89]$.

391

\section{Effects of the the material relative density on the optical properties}

393 For both series of samples, the reflectance increases with the increase in the relative density in the 394 whole range of analyzed wavelengths (Figure 5). From the near-normal spectral reflectance curves, 395 the sample total solar absorptance $(\alpha)$, the sample total directional and hemispherical thermal 396 emittances $\left(\varepsilon_{8^{\circ}}\right.$ and $\left.\varepsilon_{\mathrm{H}}\right)$ have been calculated using equations $(6),(7)$ and $(8)$ respectively. The results

397 are reported as a function of the sample relative density on Figure 6. As expected, the increase in the 398 reflectance induces a decrease in both the absorptance and the emittance.

399 The values of hemispherical emittance calculated from multi-angle data (Equation 8) were almost the 400 same as the values of directional emittance calculated from single near-normal reflectance curve 401 (Equation 7), especially for $\mathrm{SiC}$ and the composite materials. The comparison is reported in 
402 Supplementary Information 7. Therefore it can be remembered for further studies that at room 403 temperature and for this type of samples, the emittance calculated from near-normal reflectance 404 measurement is quite representative of the hemispherical emittance.

405

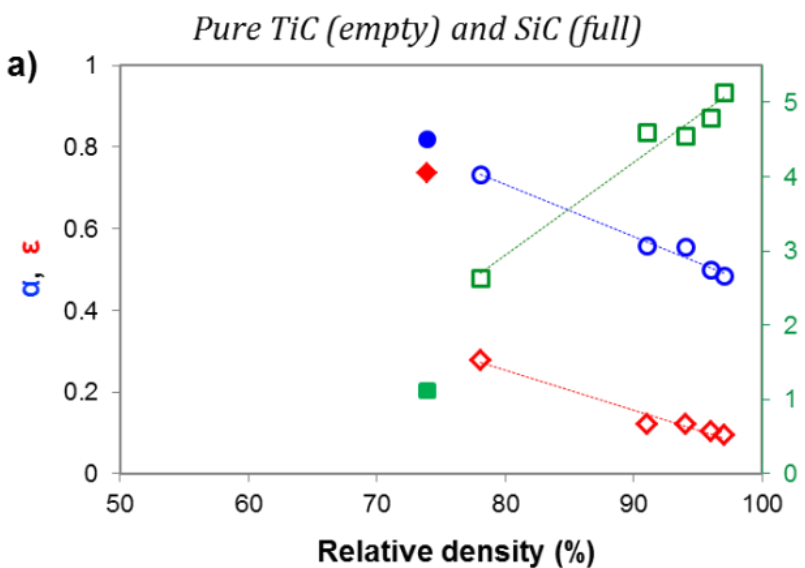

Relative density (\%)

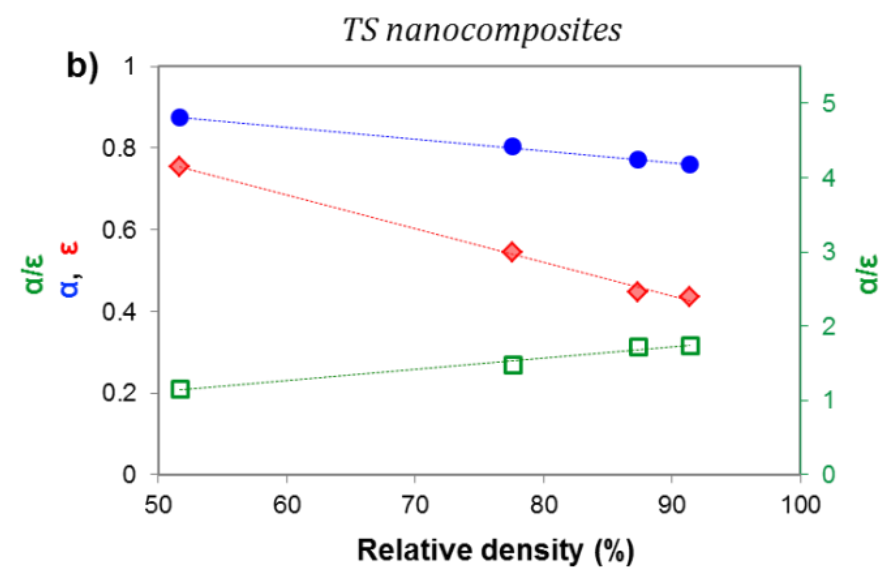

- Absorptance a

Selectivity $(\alpha / \varepsilon)$
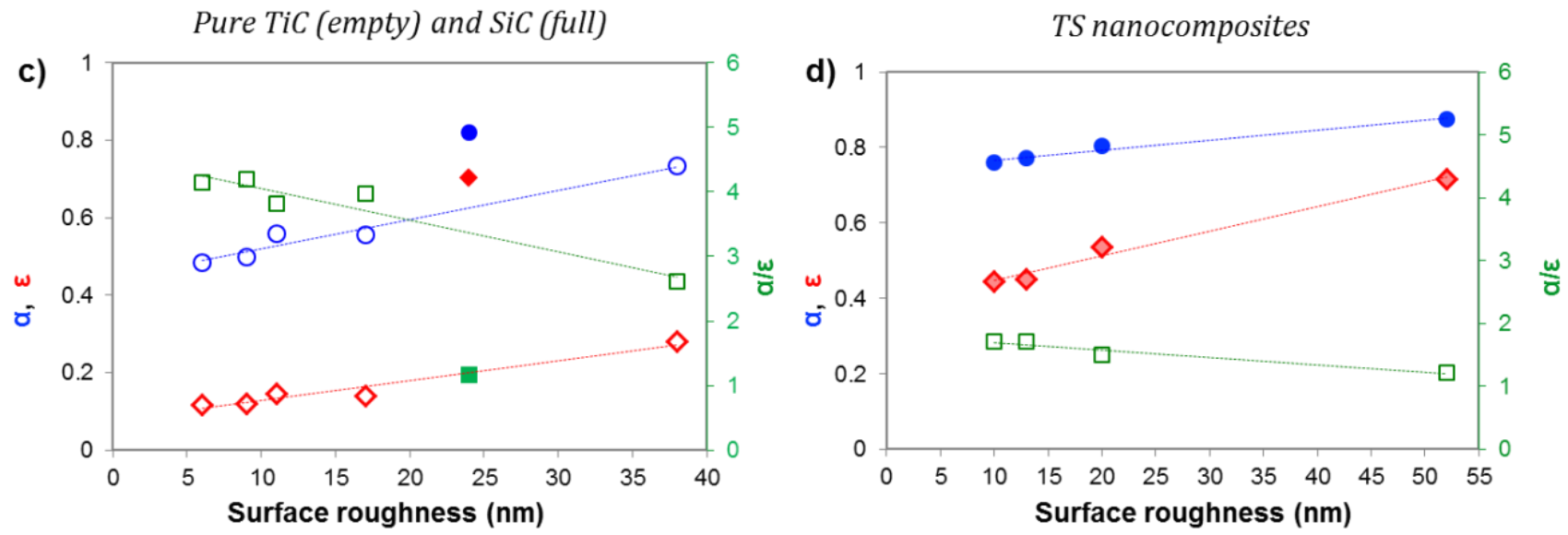

406

407 Figure 6: Evolution of the absorptance $(\alpha)$, the emittance $(\varepsilon)$ and the selectivity $(\alpha / \varepsilon)$ as a function of $(a, b)$ the relative 408 density and $(c, d)$ the surface roughness of $(a, c)$ the pure TiC and SiC samples and $(b, d)$ the composite samples.

409

410 For all samples, the selectivity (absorptance / emittance) increases with the sample relative density 411 (Figure 6-a, b) and decreases with the increase in surface roughness (Figure 6-c, d). These results are 412 consistent with those of the literature and with those of our preliminary study reported in 413 Supplementary Information 1 [19, 20, 23, 45-47]. For TS composites, the evolution of the optical 414 properties as a function of the relative density or of the surface roughness are almost linear. The 415 selectivity of samples TS-92 and TS-96 is the same. The increase in absorptance with surface 416 roughness can be explained by the multi-reflexions effect: light is trapped by the walls of the surface 417 holes and scratches. Light is reflected several times, increasing the absorptance [5, 6, 90]. The 418 increase in emittance is related to the increase in specific surface area as the surface roughness 419 increases. By definition, the quantity of energy emitted by a material is proportional to its surface. 
420 When comparing with the pure $\mathrm{SiC}$ and pure $\mathrm{TiC}$ references (Figure 6-a), it appears that all 421 nanocomposite samples (Figure 6-b) have a higher selectivity than the pure SiC reference but lower 422 that the one of the pure TiC reference. Due to their good spectral selectivity, these nanocomposite 423 materials could therefore be good candidates for bulk solar applications, especially the denser ones. 424 As TS-92 and TS-96 samples have the same value of spectral selectivity, we could consider that a 425 SPS sintering temperature of $1650^{\circ} \mathrm{C}$ is sufficient to obtain a composite with interesting optical 426 properties.

427

428 One can wonder if the effect of the sample relative density on its optical properties is only a surface 429 effect or if the bulk has to be considered. There is a tight link between relative density and surface 430 roughness, especially for the composite samples (Figure 2-c-d).

431 In the case of the composite, the two denser samples (TS-92 and TS-96) have the same spectral 432 selectivity, their reflectanec curves are almost superimposed despite a difference in relative density 433 of $4 \%$ and a difference in surface roughness of $3 \mathrm{~nm}$. In the case of the three denser TiC samples 434 (TiC-94, TiC-96, TiC-97), the difference in relative density is similar (3\%) but the difference in 435 surface roughness is much higher $(7 \mathrm{~nm})$, as well as the effects on the optical properties. Therefore, 436 the effects on the optical properties seems to be mainly due to changes in surface roughness, at least 437 for samples with a relative density higher than $90 \%$.

\section{8}

439 To thoroughly determine whether the closed porosity has an impact on the optical properties, the 440 emittance should be measured directly from the non-illuminated face of the samples and not 441 calculated from the surface reflectance curve [11]. On going work should bring new information 442 about this question.

443 The key to increase the spectral selectivity is to increase the absorptance without increasing the 444 emittance. Several ideas have been proposed in the literature, among them, the concept of directional 445 selectivity. As the incident solar radiation is directional while the radiative losses are hemispherical, 446 an optical cavity can be used to trap the incident solar radiation and reflect the emitted radiation back 447 to the absorber [91]. Similarly, Hollands et al. proposed to use corrugated specular surfaces to 448 selectively absorb the directional solar radiation while limiting the hemispherical radiation losses 449 [50]. It could also be interesting to extend the study to higher frequencies, and monitor the properties 450 of the $\mathrm{SiC}-\mathrm{TiC}$ composites as electromagnetic wave absorber as it has been done for $\mathrm{SiC} / \mathrm{Si}_{3} \mathrm{~N}$ 451 composites $[92,93]$. 


\section{Conclusion}

456 In this paper the potential of SiC-TiC nanocomposite materials for bulk solar absorber applications 457 was studied. $70 \%$ at $\mathrm{SiC}-30 \%$ at $\mathrm{TiC}$ nanocomposite materials were successfully synthesized by a 458 sol-gel route from alkoxides as metal oxide precursors and sucrose as the carbon source. The 459 carbothermal reduction was conducted at relatively low temperature $\left(1550^{\circ} \mathrm{C}\right)$ compared to the 460 conventional process. The resulting powder was composed of nanometric $\mathrm{TiC}$ and $\mathrm{SiC}$ particles 461 homogeneously mixed, with 5-7 \%wt of residual $\mathrm{O}$. The sintering process was then adapted to 462 produce compacts with various densities. Reference materials of pure TiC with increasing densities 463 were also sintered from commercial TiC powder.

464 The spectral reflectance was measured in the 0.25 to $25 \mu \mathrm{m}$ wavelength range to evaluate the spectral 465 selectivity of these materials. The effects of the sample relative density and surface roughness were 466 studied and their correlation was discussed. A tight link between the sample relative density and its 467 surface roughness was identified and explained by considering the open porosity as the main 468 contribution to surface roughness. The reflectance was found to increase in the whole wavelength 469 range, with the increase in relative density and the decrease in surface roughness. Therefore, the 470 denser and smoother the sample, the higher its spectral selectivity. The TiC-SiC composite had an 471 intermediate reflectance compared to the pure SiC and the pure TiC samples. With an absorptance of 472 0.76, an emittance of 0.44 and a selectivity of 1.74 , the denser SiC-TiC could be a good candidate for 473 bulk solar applications. Even though these values are slightly lower than those obtained for other 474 materials like $\mathrm{ZrB}_{2}$, HfC or $\mathrm{TaC}$, it should be recalled that these materials also have to be resistant to 475 oxidation which is the case of our SiC-TiC composite [21, 33, 94]. In addition, several solutions 476 from the literature were proposed to improve these optical properties by increasing the absorptance

477 while maintaining a low emittance.

\section{8}

\section{Acknowledgments}

480 This work was funded by the RBPCH project from the Nuclear Energy Division of CEA and by the 481 National Agency for Research (ANR) of the French State in the framework of the CARAPASS 482 project (award n ${ }^{\circ}$ ANR-16-CE08-0026) and of the French "Investments for the future" programme 483 managed by ANR under contracts ANR-10-LABX-22-01-SOLSTICE and ANR-10-EQPX-49484 SOCRATE. We wish to thank Renaud Podor and Joseph Lautru for SEM imaging, Bruno Corso for 485 XRD assistance, Cyrielle Rey for helium pycnometry measurements and furnace assistance and 486 Christophe Escape for his help in reflectometry measurements.

\section{Declarations of interest}

489 The authors declare no competing interests. 


\section{References}

491 [1] C.G. Granqvist, Solar energy materials, Advanced Materials 15(21) (2003) 1789-1803.

492 [2] Y. Tian, C.Y. Zhao, A review of solar collectors and thermal energy storage in solar thermal 493 applications, Applied Energy 104 (2013) 538-553.

494 [3] J. Spitz, Selective surfaces for high-temperature solar photothermal conversion, Thin Solid Films 495 45(1) (1977) 31-41.

496 [4] J. Spitz, D. Mazierebezes, Selective materials for solar-energy photothermal conversion, Journal 497 of Optics-Nouvelle Revue D Optique 15(5) (1984) 325-332.

498 [5] W.F. Bogaerts, C.M. Lampert, Materials for photothermal solar-energy conversion, Journal of 499 Materials Science 18(10) (1983) 2847-2875.

500 [6] C.M. Lampert, Coatings for enhanced photo thermal energy collection .1. Selective absorbers, 501 Solar Energy Materials 1(5-6) (1979) 319-341.

502 [7] C.C. Agrafiotis, I. Mavroidis, A.G. Konstandopoulos, B. Hoffschmidt, P. Stobbe, M. Romero, V. 503 Fernandez-Quero, Evaluation of porous silicon carbide monolithic honeycombs as volumetric 504 receivers/collectors of concentrated solar radiation, Solar Energy Materials and Solar Cells 91(6) 505 (2007) 474-488.

506 [8] E. Sani, L. Mercatelli, D. Jafrancesco, J.L. Sans, D. Sciti, Ultra-High Temperature Ceramics for 507 solar receivers: spectral and high-temperature emittance characterization, Journal of the European 508 Optical Society-Rapid Publications 7 (2012).

509 [9] H.H. Blau, J.R. Jasperse, Spectral emittance of refractory materials, Applied Optics 3(2) (1964) $510281-\&$.

511 [10] L. Mercatelli, M. Meucci, E. Sani, Design and test of a new facility for assessing spectral 512 normal emittance of solid materials at high temperature, in: S. Jiang, M.J.F. Digonnet (Eds.), Optical 513 Components and Materials Xiii2016.

514 [11] L. Mercatelli, M. Meucci, E. Sani, Facility for assessing spectral normal emittance of solid 515 materials at high temperature, Applied Optics 54(29) (2015) 8700-8705.

516 [12] E. Sani, L. Mercatelli, J.L. Sans, D. Sciti, Optical properties of black and white ZrO2 for solar 517 receiver applications, Solar Energy Materials and Solar Cells 140 (2015) 477-482.

518 [13] E. Sani, M. Meucci, L. Mercatelli, D. Jafrancesco, J.L. Sans, L. Silvestroni, D. Sciti, Optical 519 properties of boride ultrahigh-temperature ceramics for solar thermal absorbers, Journal of Photonics 520 for Energy 4 (2014).

521 [14] D. Sciti, L. Silvestroni, J.L. Sans, L. Mercatelli, M. Meucci, E. Sani, Tantalum diboride-based 522 ceramics for bulk solar absorbers, Solar Energy Materials and Solar Cells 130 (2014) 208-216.

523 [15] E. Sani, L. Mercatelli, J.L. Sans, L. Silvestroni, D. Sciti, Porous and dense hafnium and 524 zirconium ultra-high temperature ceramics for solar receivers, Optical Materials 36(2) (2013) 163 525168 .

526 [16] D. Sciti, L. Silvestroni, L. Mercatelli, J.L. Sans, E. Sani, Suitability of ultra-refractory diboride 527 ceramics as absorbers for solar energy applications, Solar Energy Materials and Solar Cells 109 528 (2013) 8-16.

529 [17] E. Sani, L. Mercatelli, D. Fontani, J.L. Sans, D. Sciti, Hafnium and tantalum carbides for high 530 temperature solar receivers, Journal of Renewable and Sustainable Energy 3(6) (2011).

531 [18] E. Sani, L. Mercatelli, F. Francini, J.L. Sans, D. Sciti, Ultra-refractory ceramics for high532 temperature solar absorbers, Scripta Materialia 65(9) (2011) 775-778.

533 [19] L. Mercatelli, E. Sani, D. Jafrancesco, P. Sansoni, D. Fontani, M. Meucci, S. Coraggia, L. 534 Marconi, J.L. Sans, E. Beche, L. Silvestroni, D. Sciti, Ultra-refractory diboride ceramics for solar 535 plant receivers, Proceedings of the Solarpaces 2013 International Conference 49 (2014) 468-477.

536 [20] E. Sani, L. Mercatelli, M. Meucci, A. Balbo, L. Silvestroni, D. Sciti, Compositional dependence 537 of optical properties of zirconium, hafnium and tantalum carbides for solar absorber 538 applications Solar Energy - 131(-) (2016) - 207.

539 [21] E. Sani, L. Mercatelli, M. Meucci, A. Balbo, C. Musa, R. Licheri, R. Orru, G. Cao, Optical 540 properties of dense zirconium and tantalum diborides for solar thermal absorbers, Renewable Energy 54191 (2016) 340-346. 
542 [22] E. Sani, E. Landi, D. Sciti, V. Medri, Optical properties of ZrB2 porous architectures, Solar 543 Energy Materials and Solar Cells 144 (2016) 608-615.

544 [23] E. Sani, L. Mercatelli, M. Meucci, L. Silvestroni, A. Balbo, D. Sciti, Process and composition 545 dependence of optical properties of zirconium, hafnium and tantalum borides for solar receiver 546 applications, Solar Energy Materials and Solar Cells 155 (2016) 368-377.

547 [24] E. Sani, M. Meucci, L. Mercatelli, A. Balbo, C. Musa, R. Licheri, R. Orru, G. Cao, Titanium 548 diboride ceramics for solar thermal absorbers, Solar Energy Materials and Solar Cells 169 (2017) 549 313-319.

550 [25] L. Charpentier, M. Balat-Pichelin, D. Sciti, L. Silvestroni, High temperature oxidation of Zr551 and Hf-carbides: Influence of matrix and sintering additive, Journal of the European Ceramic Society 552 33(15-16) (2013) 2867-2878.

553 [26] L. Charpentier, M. Balat-Pichelin, E. Beche, D. Sciti, L. Silvestroni, Microstructural 554 characterization of $\mathrm{ZrC}-\mathrm{MoSi} 2$ composites oxidized in air at high temperatures, Applied Surface 555 Science 283 (2013) 751-758.

556 [27] A. Onuma, H. Kiyono, S. Shimada, M. Desmaison, High temperature oxidation of sintered TiC 557 in an H2O-containing atmosphere, Solid State Ionics 172(1-4) (2004) 417-419.

558 [28] S. Shimada, A thermoanalytical study on the oxidation of $\mathrm{ZrC}$ and HfC powders with formation 559 of carbon, Solid State Ionics 149(3-4) (2002) 319-326.

560 [29] S. Shimada, K. Mochidsuki, The oxidation of TiC in dry oxygen, wet oxygen, and water vapor, 561 Journal of Materials Science 39(2) (2004) 581-586.

562 [30] M. Gherrab, V. Garnier, S. Gavarini, N. Millard-Pinard, S. Cardinal, Oxidation behavior of 563 nano-scaled and micron-scaled TiC powders under air, International Journal of Refractory Metals \& 564 Hard Materials 41 (2013) 590-596.

565 [31] J. Sempere, R. Nomen, E. Serra, B. Sempere, D. Guglielmi, Thermal behavior of oxidation of $566 \mathrm{TiN}$ and TiC nanoparticles, Journal of Thermal Analysis and Calorimetry 105(2) (2011) 719-726.

567 [32] V.V. Rudneva, G.V. Galevskii, Investigation of thermal oxidation resistance of nanopowders of 568 refractory carbides and borides, Russian Journal of Non-Ferrous Metals 48(2) (2007) 143-147.

569 [33] M. Coulibaly, G. Arrachart, A. Mesbah, X. Deschanels, From colloidal precursors to metal 570 carbides nanocomposites $\mathrm{MC}(\mathrm{M}=\mathrm{Ti}, \mathrm{Zr}, \mathrm{Hf}$ and $\mathrm{Si})$ : Synthesis, characterization and optical spectral 571 selectivity studies, Solar Energy Materials and Solar Cells 143 (2015) 473-479.

572 [34] J. Cabrero, F. Audubert, R. Pailler, Fabrication and characterization of sintered TiC-SiC 573 composites, Journal of the European Ceramic Society 31(3) (2011) 313-320.

574 [35] J. Chen, W.J. Li, W. Jiang, Characterization of sintered TiC-SiC composites, Ceramics 575 International 35(8) (2009) 3125-3129.

576 [36] K.S. Cho, Y.W. Kim, H.J. Choi, J.G. Lee, In situ-toughened silicon carbide-titanium carbide 577 composites, Journal of the American Ceramic Society 79(6) (1996) 1711-1713.

578 [37] H. Endo, M. Ueki, H. Kubo, Hot-pressing of SiC-TiC composites, Journal of Materials Science 579 25(5) (1990) 2503-2506.

580 [38] H. Endo, M. Ueki, H. Kubo, Microstructure and mechanical-properties of hot-pressed SiC-TiC 581 composites, Journal of Materials Science 26(14) (1991) 3769-3774.

582 [39] Y.M. Luo, S.Q. Li, P. Wei, L. Liu, Fabrication and mechanical evaluation of SiC-TiC 583 nanocomposites by SPS, Materials Letters 58(1-2) (2004) 150-153.

584 [40] D. Shaoming, J. Dongliang, T. Shouhong, G. Jingkun, Mechanical properties of SiC/TiC 585 composites by hot isostatic pressing, Journal of Materials Science Letters 15(5) (1996) 394-396.

586 [41] G.C. Wei, P.F. Becher, Improvements in mechanical-properties in SiC by the addition of TiC 587 particles, Journal of the American Ceramic Society 67(8) (1984) 571-574.

588 [42] M.A. Janney, Microstructural development and mechanical-properties of SiC and SiC-TiC 589 composites, American Ceramic Society Bulletin 65(2) (1986) 357-362.

590 [43] L.J. Wang, W. Jiang, L.D. Chen, S.Q. Bai, Rapid reactive synthesis and sintering of submicron $591 \mathrm{TiC} / \mathrm{SiC}$ composites through spark plasma sintering, Journal of the American Ceramic Society 87(6) 592 (2004) 1157-1160. 
593 [44] M. Khodaei, O. Yaghobizadeh, H.R. Baharvandi, A. Dashti, Effects of different sintering 594 methods on the properties of $\mathrm{SiC}-\mathrm{TiC}, \mathrm{SiC}-\mathrm{TiB} 2$ composites, International Journal of Refractory 595 Metals \& Hard Materials 70 (2018) 19-31.

596 [45] D. Sciti, L. Silvestroni, L. Mercatelli, J.-L. Sans, E. Sani, Suitability of ultra-refractory diboride 597 ceramics as absorbers for solar energy applications, Solar Energy Materials and Solar Cells 109 598 (2013) 8-16.

599 [46] D. Sciti, L. Silvestroni, J.-L. Sans, L. Mercatelli, M. Meucci, E. Sani, Tantalum diboride-based 600 ceramics for bulk solar absorbers, Solar Energy Materials and Solar Cells 130 (2014) 208-216.

601 [47] E. Sani, L. Mercatelli, M. Meucci, L. Zoli, D. Sciti, Lanthanum hexaboride for solar energy 602 applications, Scientific Reports 7 (2017).

603 [48] D. Sciti, L. Silvestroni, D.M. Trucchi, E. Cappelli, S. Orlando, E. Sani, Femtosecond laser 604 treatments to tailor the optical properties of hafnium carbide for solar applications, Solar Energy 605 Materials and Solar Cells 132 (2015) 460-466.

606 [49] D. Sciti, D.M. Trucchi, A. Bellucci, S. Orlando, L. Zoli, E. Sani, Effect of surface texturing by 607 femtosecond laser on tantalum carbide ceramics for solar receiver applications, Solar Energy 608 Materials and Solar Cells 161 (2017) 1-6.

609 [50] K.G.T. Hollands, Directional selectivity, emittance and absorptance properties of eve corrugated 610 specular surfaces, Solar Energy 7(3) (1963) 108-116.

611 [51] E.G. Acheson, Manufacture of graphite, Google Patents, 1896.

612 [52] N.A. Hassine, J.G.P. Binner, T.E. Cross, Synthesis of refractory-metal carbide powders via 613 microwave carbothermal reduction, International Journal of Refractory Metals \& Hard Materials 614 13(6) (1995) 353-358.

615 [53] M.D. Sacks, C.A. Wang, Z.H. Yang, A. Jain, Carbothermal reduction synthesis of 616 nanocrystalline zirconium carbide and hafnium carbide powders using solution-derived precursors, 617 Journal of Materials Science 39(19) (2004) 6057-6066.

618 [54] V.M. Kevorkijan, M. Komac, D. Kolar, Low-temperature synthesis of sinterable SiC powders 619 by carbothermic reduction of colloidal SiO2, Journal of Materials Science 27(10) (1992) 2705-2712.

620 [55] Y.J. Lin, C.P. Tsang, The effects of starting precursors on the carbothermal synthesis of SiC 621 powders, Ceramics International 29(1) (2003) 69-75.

622 [56] H.P. Martin, R. Ecke, E. Muller, Synthesis of nanocrystalline silicon carbide powder by 623 carbothermal reduction, Journal of the European Ceramic Society 18(12) (1998) 1737-1742.

624 [57] A. Julbe, A. Larbot, C. Guizard, L. Cot, J. Charpin, P. Bergez, Effect of boric-acid addition in 625 colloidal sol-gel derived SiC precursors, Materials Research Bulletin 25(5) (1990) 601-609.

626 [58] V.D. Krstic, Production of fine, high-purity beta silicon-carbide powders, Journal of the 627 American Ceramic Society 75(1) (1992) 170-174.

628 [59] X. Deschanels, D. Herault, G. Arrachart, C. Rey, A. Grandjean, G. Toquer, R. Podor, T. Zemb, 629 G. Cerveau, R. Corriu, Comparison of two soft chemistry routes for the synthesis of mesoporous 630 carbon/beta-SiC nanocomposites, Journal of Materials Science 48(11) (2013) 4097-4108.

631 [60] M. Coulibaly, Carbures nanocomposites issus de précurseurs s ol-gel et impacts sur la sélectivité 632 optique Montpellier, 2015.

633 [61] K. Thorne, S.J. Ting, C.J. Chu, J.D. Mackenzie, T.D. Getman, M.F. Hawthorne, Synthesis of $634 \mathrm{TiC}$ via polymeric titanates - the preparation of fibres and thin-films, Journal of Materials Science 635 27(16) (1992) 4406-4414.

636 [62] P. Gupta, W. Wang, L.S. Fan, Synthesis of high-surface-area SiC through a modified Sol-Gel 637 route: Control of the pore structure, Industrial \& Engineering Chemistry Research 43(16) (2004) $6384732-4739$.

639 [63] S.M. El-Sheikh, Z.I. Zaki, Y.M.Z. Ahmed, In situ synthesis of ZrC/SiC nanocomposite via 640 carbothermic reduction of binary xerogel, Journal of Alloys and Compounds 613 (2014) 379-386.

641 [64] J. Zhong, S.Q. Liang, K. Wang, H.T. Wang, T. Williams, H. Huang, Y.B. Cheng, Synthesis of 642 Mesoporous Carbon-Bonded TiC/SiC Composites by Direct Carbothermal Reduction of Sol-Gel 643 Derived Monolithic Precursor, Journal of the American Ceramic Society 94(11) (2011) 4025-4031. 
644 [65] H. Zhang, F. Li, Q. Jia, G. Ye, Preparation of titanium carbide powders by sol-gel and 645 microwave carbothermal reduction methods at low temperature, Journal of Sol-Gel Science and 646 Technology 46(2) (2008) 217-222.

647 [66] R. Corriu, P. Gerbier, C. Guerin, B. Henner, The thermal-conversion of poly(silylene)648 diacetylene metal-oxide composites - A new approach to beta-SiC-MC ceramics, Angewandte 649 Chemie-International Edition in English 31(9) (1992) 1195-1197.

650 [67] R.J.P. Corriu, Ceramics and nanostructures from molecular precursors, Angewandte Chemie651 International Edition 39(8) (2000) 1376-1398.

652 [68] R.J.P. Corriu, P. Gerbier, C. Guerin, B. Henner, From preceramic polymers with 653 interpenetrating networks to SiC/MC nanocomposites, Chemistry of Materials 12(3) (2000) 805-811. 654 [69] X. Deschanels, M. El Ghazzal, C. Delchet, D. Herault, V. Magnin, A. Grandjean, R. Podor, G. 655 Cerveau, T. Zemb, R. Corriu, Synthesis of carbide compounds derived from colloidal oxide and 656 carbohydrate, in: S. Bucak (Ed.), Trends in Colloid and Interface Science Xxiii2010, pp. 47-52.

657 [70] S.T. Bae, H. Shin, H.S. Jung, K.S. Hong, Synthesis of Titanium Carbide Nanoparticles with a 658 High Specific Surface Area from a TiO2 Core-Sucrose Shell Precursor, Journal of the American 659 Ceramic Society 92(11) (2009) 2512-2516.

660 [71] C. Ang, T. Williams, A. Seeber, H.T. Wang, Y.B. Cheng, Synthesis and Evolution of Zirconium 661 Carbide via SolGel Route: Features of Nanoparticle OxideCarbon Reactions, Journal of the 662 American Ceramic Society 96(4) (2013) 1099-1106.

663 [72] D. Hanaor, M. Michelazzi, C. Leonelli, C.C. Sorrell, The effects of carboxylic acids on the 664 aqueous dispersion and electrophoretic deposition of $\mathrm{ZrO} 2$, Journal of the European Ceramic Society $66532(1)$ (2012) 235-244.

666 [73] S. Mahata, B. Mondal, S.S. Mahata, K. Usha, N. Mandal, K. Mukherjee, Chemical modification 667 of titanium isopropoxide for producing stable dispersion of titania nano-particles, Materials 668 Chemistry and Physics 151 (2015) 267-274.

669 [74] I.A. Mudunkotuwa, V.H. Grassian, Citric Acid Adsorption on TiO2 Nanoparticles in Aqueous 670 Suspensions at Acidic and Circumneutral pH: Surface Coverage, Surface Speciation, and Its Impact 671 on Nanoparticle-Nanoparticle Interactions, Journal of the American Chemical Society 132(42) 672 (2010) 14986-14994.

673 [75] M.M. Barbooti, D.A. Alsammerrai, Thermal-decomposition of citric-acid, Thermochimica Acta 67498 (1986) 119-126.

675 [76] D. Wyrzykowski, E. Hebanowska, G. Nowak-Wiczk, M. Makowski, L. Chmurzynski, Thermal 676 behaviour of citric acid and isomeric aconitic acids, Journal of Thermal Analysis and Calorimetry 677 104(2) (2011) 731-735.

678 [77] T. Sadik, C. Pillon, C. Carrot, J.A.R. Ruiz, Dsc studies on the decomposition of chemical 679 blowing agents based on citric acid and sodium bicarbonate, Thermochimica Acta 659 (2018) 74-81.

680 [78] R. Belon, G. Antou, N. Pradeilles, A. Maitre, D. Gosset, Mechanical behaviour at high 681 temperature of spark plasma sintered boron carbide ceramics, Ceramics International 43(8) (2017) 682 6631-6635.

683 [79] G. Antou, N. Pradeilles, M. Gendre, A. Maitre, New approach of the evolution of densification 684 mechanisms during Spark Plasma Sintering: Application to zirconium (oxy-)carbide ceramics, 685 Scripta Materialia 101 (2015) 103-106.

686 [80] T. Roisnel, J. Rodriguez-Carvajal, WinPLOTR: A Windows tool for powder diffraction pattern 687 analysis, Epdic 7: European Powder Diffraction, Pts 1 and 2 378-3 (2001) 118-123.

688 [81] J. Rodriguez-Carvajal, Recent advances in magnetic-structure determination by neutron powder 689 diffraction, Physica B 192(1-2) (1993) 55-69.

690 [82] M. Mashhadi, H. Khaksari, S. Safi, Pressureless sintering behavior and mechanical properties of $691 \mathrm{ZrB} 2-\mathrm{SiC}$ composites: effect of $\mathrm{SiC}$ content and particle size, Journal of Materials Research and 692 Technology-Jmr\&T 4(4) (2015) 416-422.

693 [83] M. Mashhadi, M. Shambuli, S. Safi, Effect of MoSi2 addition and particle size of SiC on 694 pressureless sintering behavior and mechanical properties of $\mathrm{ZrB} 2-\mathrm{SiC}-\mathrm{MoSi} 2$ composites, Journal 695 of Materials Research and Technology-Jmr\&T 5(3) (2016) 200-205. 
696 [84] P. Barick, D. Chakravarty, B.P. Saha, R. Mitra, S.V. Joshi, Effect of pressure and temperature 697 on densification, microstructure and mechanical properties of spark plasma sintered silicon carbide 698 processed with beta-silicon carbide nanopowder and sintering additives, Ceramics International 699 42(3) (2016) 3836-3848.

700 [85] N.Z. Khalil, S.K. Vajpai, M. Ota, K. Ameyama, Effect of Particle Size Distribution on SiC 701 Ceramic Sinterability, Materials Transactions 56(11) (2015) 1827-1833.

702 [86] A. Lara, A.L. Ortiz, A. Munoz, A. Dominguez-Rodriguez, Densification of additive-free 703 polycrystalline beta-SiC by spark-plasma sintering, Ceramics International 38(1) (2012) 45-53.

704 [87] B. Jiang, N. Hou, S. Huang, G. Zhou, J. Hou, Z. Cao, H. Zhu, Structural studies of TiC1-xOx 705 solid solution by Rietveld refinement and first-principles calculations, Journal of Solid State 706 Chemistry 204 (2013) 1-8.

707 [88] O. Tengstrand, N. Nedfors, B. Alling, U. Jansson, A. Flink, P. Eklund, L. Hultman, 708 Incorporation effects of Si in TiCx thin films, Surface \& Coatings Technology 258 (2014) 392-397.

709 [89] F. Réjasse, O. Rapaud, J. Léchelle, G. Trolliard, H. Khodja, O. Masson, G. Martin, A. Maître, 710 Novel insight into the chemical analysis of light elements in oxycarbides, Acta materialia 157 (2018) $71111-20$.

712 [90] G. Pellegrini, Experimental methods for the preparation of selectively absorbing textured 713 surfaces for photo thermal solar conversion, Solar Energy Materials 3(3) (1980) 391-404.

714 [91] L. Weinstein, D. Kraemer, K. McEnaney, G. Chen, Optical cavity for improved performance of 715 solar receivers in solar-thermal systems, Solar Energy 108 (2014) 69-79.

716 [92] P. Wang, L.F. Cheng, Y.N. Zhang, L.T. Zhang, Flexible SiC/Si3N4 Composite Nanofibers with 717 in Situ Embedded Graphite for Highly Efficient Electromagnetic Wave Absorption, Acs Applied 718 Materials \& Interfaces 9(34) (2017) 28844-28858.

719 [93] P. Wang, L.F. Cheng, L.T. Zhang, One-dimensional carbon/SiC nanocomposites with tunable 720 dielectric and broadband electromagnetic wave absorption properties, Carbon 125 (2017) 207-220.

721 [94] E. Sani, L. Mercatelli, M. Meucci, A. Balbo, L. Silvestroni, D. Sciti, Compositional dependence 722 of optical properties of zirconium, hafnium and tantalum carbides for solar absorber applications, 723 Solar Energy 131 (2016) 199-207. 